\title{
Letters
}

\section{Nutrition, dehydration and the terminally ill}

SIR

Your correspondents Dr Stone and Dr Phillips have made some comments on my paper, which was critical of some aspects of palliative medicine (1). They claim that many of my fears were misplaced 'because of a misunderstanding of current practice in palliative medicine'. My paper was the outcome of close observation of current practice, profound concern about what I observed, and examination of relevant literature up to 1992 .

Dr Stone and Dr Phillips concede that when patients are symptomatic, ie they complain of thirst but cannot swallow, palliative care physicians will supply fluids artificially. They outline several situations where fluids would not be given, and stray widely from the central theme of my paper which was the issue of the need for artificial hydration when a person is rendered incapable of swallowing by sedation. I am not talking about 'a certain amount of physiological dehydration' in the dying process, but of gross, iatrogenic dehydration. As I pointed out if sedation is continued without hydration, death from dehydration will be inevitable, whatever the underlying pathology, within about seven days. Of course death from natural causes may occur first, but the longer the interval between sedation and death, the greater will be the dehydration element in the aetiology.

Your correspondents refer to a letter written by Waller et al (2) which purports to show that in dying patients the level of consciousness is not affected by the use or non-use of intravenous (IV) fluids. The data does not stand up to scrutiny. Waller measured some biochemical parameters and the level of consciousness in 68 cancer patients during the last 48 hours of life. It is possible to calculate from the information given that the mean blood urea of all 68 patients at some stage (presumably on admission) was $21.64 \mathrm{mmol} / \mathrm{l}$. Thirteen patients received IV fluids in unspecified amounts, for unspecified lengths of time, either because they were receiving them on transfer, or after family members' requests. The initial blood urea results in this sub-group of patients are not given. We are told that the mean blood urea - presumably at the end of the study - did not differ in those given, or not given IV fluids, the values being 50.9 and 54.5 $\mathrm{mmol} / 1$. Serum sodium was significantly lower in the treated than the untreated group. Level of consciousness did not correlate with the use or non-use of IV fluids, but it did correlate with serum sodium concentration. Serum potassium levels were dangerously high (mean $7 \cdot 25 \mathrm{mmol} / \mathrm{l}$ ) in 31 out of 68 patients. This unsatisfactory study does not demonstrate that 'there is a difference between the acute and the dying patient' as Drs Stone and Phillips claim. The high blood urea in the 'treated' group suggests that rehydration was inadequate. The report confirms that many patients in a palliative care setting have no treatment, or inadequate treatment for severe dehydration and electrolyte imbalance.

Drs Stone and Phillips argue that a patient who is sedated for delirium may become dehydrated more slowly than an unsedated delirious person. This may be true, but the evidence is lacking. What is certain is that with the passage of time fatal dehydration will occur in both situations unless adequate amounts of fluid are given. Your correspondents state that the principal reason that a drip is not sited in palliative care is futility', but opinions as to what is futile and what is not can vary widely. In cases of doubt, especially where survival outcome is uncertain, the balance should be weighted in favour of prolonging life. Relatives' views should be carefully heeded, if the symptoms of pathological grief and post-traumatic stress are to be avoided.

Your correspondents finally retreat behind a wall of conventional jargon, accusing me of 'medicalising dying'. This does not move the debate forward. My concern is about medicalising dying in a literal sense, that is by the giving of medication that may hasten death, if side-effects are ignored.

May I assure Drs Stone and Phillips that recent work indicates that patients dying at home who need sedation, do not necessarily have to be admitted for IV fluids. Dame Cicely Saunders is 'finding a real use in the subcutaneous route which can be used at home ...' (3).

The ethics committee of the Association for Palliative Medicine discussed the issues raised in my paper, including the need to ensure that the wishes of patient and family are not disregarded by any global policy of a unit, and the need to look at hydration as a specific patient need. I hope that they will publish a detailed response. Dr Ilora Finlay, the chairperson, expressing her personal opinion, wrote: 'I would agree wholeheartedly that individual assessments must be made, and that rehydration can provide effective symptomatic relief as well as being life-prolonging. The ease with which subcutaneous fluids can be given means that venous access is not a prerequisite' (4).

Professor Hanks, writing in his capacity as Director of the Cancer Relief Macmillan Fund said: 'The subject raised by your paper concerns a frequent therapeutic dilemma in palliative care practice. The overriding principle in dealing with it must be to tailor the management to the individual patient. Thus in some patients intervention with intravenous or subcutaneous fluids is certainly indicated, whereas for others this is an inappropriate course. I am sure that a blanket policy is wrong ...' (5). Professor 
Hanks did not address the profound ethical issues.

The House of Lords Select Committee on Medical Ethics discussed the issue of nutrition and hydration in the terminally ill in relation to the Bland case, but the principles have wider application. They made it clear that it should be unnecessary to consider the withdrawal (or non-introduction) of nutrition or hydration except in circumstances where its administration is in itself a burden to the patient (6). Legal aspects remain unresolved (7). Further debate is needed.

\section{References}

(1) Craig G M. On withholding nutrition and hydration in the terminally ill: has palliative medicine gone too far? fournal of medical ethics 1994; 20: 139-143.

(2) Waller A, Adunski A, Hershkowitz M. Terminal dehydration and intravenous fluids [letter]. Lancet 1991; 337: 745.

(3) Saunders C. Personal communication 1994 Oct.

(4) Finlay I. Personal communication 1994 Nov.

(5) Hanks G W. Personal communication Dec 1994.

(6) House of Lords Select Committee on Medical Ethics Report. London: HMSO, 1994: Paras 251-257: Treatment limiting decisions.

(7) Craig G M. Is sedation without hydration or nourishment in terminal care lawful? Medico-legal journal 1994; 62: 198-201.

DR G M CRAIG 118 Cedar Road East Abington

Northampton NN3 $2 f F$

\section{Medical information}

\section{SIR}

\section{Total dissemination of medical information}

There is a conflict between the author's wish for total dissemination and the limitation of the printrun of journals. Although journals might have 2 nd and 3rd readers, the limitations to readership are clear.

The limitation of the audience of the publication the author has chosen makes total dissemination difficult. It is not only in the interest of the author to have his or her opinion, or the results of his or her investigation, disseminated. It is also in the interest of global health that medical information is transferred to the largest audience possible.

\section{Free transfer of medical information?}

Since 1984 I have been editor of a medical journal directed at general physicians, in former Comecon areas. The journal started with one edition for the former USSR and is financed by subscriptions and advertising. It has a controlled circulation. Strict separation of editorial matters and economic results is guaranteed by a grant from a foundation. The journal is published as a non-profit service to the medical profession.

It is understood that doctors should not charge their colleagues for medical services. Does that include medical information, too? Would it be 'proper' to charge a colleague in another country for medical information?

Normally authors contribute medical scientific articles without any financial compensation. It is understood that the 'publish or perish' obligation makes financial compensation an item that is simply not discussed. Members of our board of consultants accept nomination to the board without any financial compensation. Travel and other outlays might be reimbursed by the publisher. Declaration of interest in pharmaceutical-related investigations is disclosed on request of the publisher. Special relationships with the pharmaceutical industry are not advanced voluntarily.

It is our policy also to select abstracts from major journals and then translate them into foreign languages. In order to avoid any misunderstandings because of difficulties of absolutely exact translation, I include the original abstract too. This serves as a control to prevent mistakes in translation. It also helps the reader to get acquainted with medical English. It is a sort of medical-information journal with, as a side-effect, a medical English course. For a complete original article (most of the time review articles) permission by letter is requested from the author for republication. Sometimes I get no answer, sometimes I am referred to the journal's editor, sometimes I get permission. It is a bit at random that permission is given. The intention of this effort is the free transfer of medical scientific information from the industrialized west to the less industrialized countries of Eastern Europe. Medical scientific information is not available in its plurality and diversity in Eastern Europe. Readerreply-card returns of 20 per cent and more indicate the need for, and appreciation of, this publication.

Health information for the developing world seems to be a topic which is gaining the attention of top medical journals. Regularly one finds requests from individuals, hospitals and organizations for medical literature.

A publisher transfers scientific information to a larger audience and is economically rewarded for this. From the economical point of view the decision to publish an original contribution should have enough financial reward to make it economically viable. It forms part of his marketing mix whereby he creates a certain image. This image is then projected towards authors and readers.

Reprints and sale of foreign rights is - and should - not be taken into account by feasibility studies of medical journals. Thus the publication of the British Medical fournal as the journal of the British Medical Association (BMA) should not consider the possibility of a foreign edition as an underlying factor for the economic survival and continuity of the journal.

Re-publication in other languages The author's wish for the greatest dissemination of the results of his study are in accordance with the interest of global health. The general public and the medical community favour reprints or re-publications of a study in foreign languages. The medical society in 'Foreignland' has little or no access to the top medical journals. Because of the native language being 'foreign', publications do not reach it. Its level of wealth being below the average for the industrialized world deprives the medical community of that country of necessary top-of-theline information. This will keep Foreignland forever on a lower level of quality care. The financial limitations of Foreignland; the ability to read foreign languages and the availability of top medical journals to the medical community create a class society. Only those with access to international gatherings will be able to keep themselves up to date. The monopoly of medical information is restricted to those who have English as a second language. There remains a feeling that a conflict of interest exists between the need for the free transfer of medical information and copyright. 